\title{
Prevalence and Presentation of Paediatric Coronavirus Disease 2019 in Lagos, Nigeria
}

\author{
Abideen Salako $\left(\mathbb{D},{ }^{1}\right.$ Oluwatosin Odubela $\mathbb{D}^{1},{ }^{1}$ Tomilola Musari-Martins $\mathbb{D}^{1},{ }^{1}$ \\ Priscilla Ezemelue $\mathbb{D D}^{1}{ }^{1}$ Titilola Gbaja-Biamila ${ }^{(D)},{ }^{1}$ Babasola Opaneye, ${ }^{1}$ Ayorinde James $\mathbb{D}^{1}{ }^{1}$ \\ Osaga Oforomeh $\mathbb{D}^{1}{ }^{1}$ Kazeem Osuolale ${ }^{D},{ }^{1}$ Adesola Musa, ${ }^{1}$ Emelda Chukwu ${ }^{1}{ }^{1}$ \\ Nurudeen Rahman $\mathbb{D}^{1},{ }^{1}$ Agatha David $\mathbb{D}^{1},{ }^{1}$ Rosemary Audu ${ }^{\mathbb{D}},{ }^{1}$ Oliver Ezechi ${ }^{\mathbb{D}}{ }^{1}$ \\ and Babatunde Salako ${ }^{1,2}$
}

${ }^{1}$ Nigerian Institute of Medical Research, Yaba, Lagos State, Nigeria

${ }^{2}$ College of Medicine, University College Hospital, Ibadan, Oyo State, Nigeria

Correspondence should be addressed to Oluwatosin Odubela; odubstosin08@gmail.com

Received 7 May 2021; Revised 1 June 2021; Accepted 8 September 2021; Published 6 October 2021

Academic Editor: Alessandro Mussa

\begin{abstract}
Copyright (c) 2021 Abideen Salako et al. This is an open access article distributed under the Creative Commons Attribution License, which permits unrestricted use, distribution, and reproduction in any medium, provided the original work is properly cited.
\end{abstract}

\begin{abstract}
Background. The objective of this study was to describe the prevalence and clinical features of coronavirus disease 2019 (COVID19) among children ( $\leq 18$ years) evaluated for Severe Acute Respiratory Syndrome Coronavirus 2 (SARS-CoV-2) infection at a testing centre in Lagos, Nigeria. Methodology. This was a retrospective study. Data on the sociodemographic, clinical characteristics and SARS-CoV-2 results of participants at a modified drive-through centre for COVID-19 test sample collection over four months were retrieved from the electronic medical records (EMR). Data obtained were analyzed using SPSS version 22.0. Results. A total of 307 children ( $\leq 18$ years) were evaluated in this review. The prevalence of SARS-CoV-2 infection among the paediatric population was $16.3 \%$. The median age (interquartile range (IQR)) was 9 (4-14) years. Common symptoms reported by the positive cases were fever $(40.0 \%)$, cough $(32.9 \%)$, sore throat $(17.1 \%)$, and runny nose $(15.7 \%)$. The majority of the positive cases had mild symptoms. Fever and sore throat were associated with the positive cases. Conclusion. Fever and sore throat were associated with SARS-CoV-2 infection among our cohort which buttresses the need for a high level of suspicion and clinical acumen in the management of common febrile diseases in paediatric settings.
\end{abstract}

\section{Introduction}

The current pandemic of the novel coronavirus disease 2019 (COVID-19) caused by the Severe Acute Respiratory Syndrome Coronavirus 2 (SARS-CoV-2) has ravaged the global community since it was first reported in the Hubei province, Wuhan, China, in December 2019. The disease has affected persons of all ages, with the elderly and individuals with underlying comorbid illness being most severely affected [1-3]. The ripple effects of the disease on global health and the economy warranted the World Health Organization (WHO) to declare it a public health emergency of international concern (PHEIC) in January $2020[4,5]$.
Nigeria, a nation with a population of over 200 million citizens (42\% are within the paediatric age group) [6], has recorded over twenty-five thousand cases and five hundred and ninety mortalities from the disease as of June 2020 since the first confirmed case on 27th February 2020 [7]. Nigeria, like most African nations, has recorded fewer cases and deaths when compared to developed countries. However, most reports of the pandemic in the country are largely silent on the pattern and prevalence of the disease among the paediatric population. The few reports on SARS-CoV-2 among the paediatric population raise pertinent questions: "are children dying unrecognized" and "are the incidence and severity of COVID-19 truly low in the paediatric age 


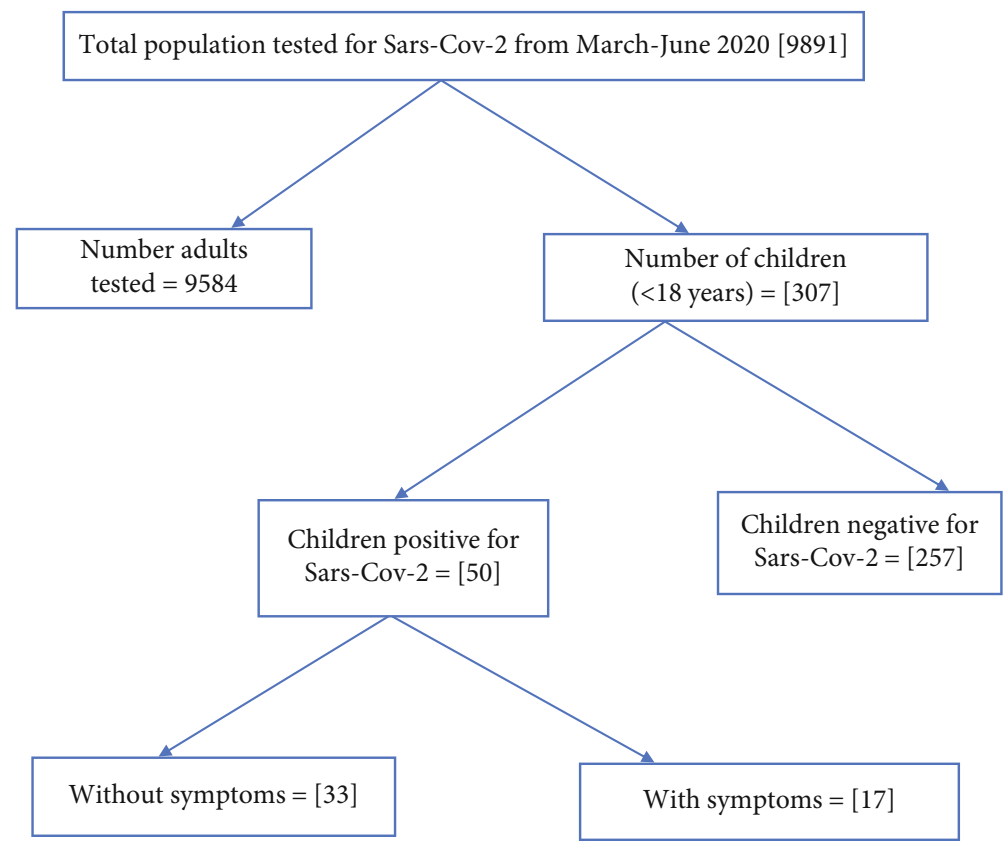

FIgURE 1: Flowchart of data review.

group" [8-10]. The nonspecific nature of the disease and the similitude to other common childhood illnesses (ranging from acute respiratory tract infection (ARI), malaria, and acute diarrheal disease) could pose a challenge in the prompt diagnosis of SARS-CoV-2 infection in the paediatric population. This study is aimed at reviewing the data on screening for SARS-CoV-2 infection and thus describing the pattern of symptomatology and prevalence of COVID-19 among children tested for COVID-19 disease in Lagos, Nigeria.

\section{Materials and Methods}

This is a retrospective study describing the symptomatology and prevalence of COVID-19 among children at a testing centre. Data was collected from the electronic records of individuals visiting the modified drive-through SARS-CoV-2 testing centre, at the Nigerian Institute of Medical Research (NIMR), Lagos, from March 1, 2020, to June 30, 2020. The institute houses two national reference laboratories: the Centre for Tuberculosis Research (CTR) and the Centre for Human Virology and Genomics (CHVG). The CHVG is an ISO 15189 -accredited laboratory involved in the diagnosis of viral infections and is also a WHO prequalification evaluating laboratory. The centre is a designated SARS-CoV-2 testing laboratory in the national network for COVID-19 laboratories.

A modified drive-through sample collection strategy was established for SARS-COV-2 testing at NIMR. The modalities of the registration and subsequent invitation to the centre have been described in a previous study [11]. The sociodemographic data (age, sex, place of and residence), travel history, preexisting comorbidities, clinical symptoms, and outcomes of the qualitative RT-PCR results (by Roche Cobas 6800) were extracted and analyzed using SPSS software, version 22.0 (IBM, Armonk, NY, USA). Categorical variables were presented as frequencies and percentages, while continuous variables were expressed as median (interquartile range). The chi-square or Fisher exact test was used to compare the differences between groups for categorical variables. Logistic regression (univariate and multivariate) was used to determine the association between study outcome and characteristics of participants. Results were considered statistically significant at $p<0.05$.

The local health authorities (Nigeria Centre for Disease Control) have defined mild cases of COVID-19 as asymptomatic and those with nonspecific symptoms (fever, cough, sore throat, nasal congestion, malaise, headache, muscle pain, loss of smell, loss of taste, diarrhea, vomiting, and abdominal pain) [12]. BCG vaccination was assessed through visual inspection of BCG scar and reporting by caregivers. Recent travel history is defined as a voyage within the last 2 weeks from a country with a higher prevalence of COVID-19 cases which correlates with the incubation period for the disease.

The Institutional Review Board of the Nigerian Institute of Medical Research approved the study protocol. Obtained data were analyzed anonymously.

\section{Results}

Of the 9891 clients screened at the NIMR centre during the period under review, 307 (3.1\%) were children ( $<18$ years). 50 children had positive results for SARS-CoV-2 giving a prevalence of $16.3 \%$. Seventeen $(34.0 \%)$ of the SARS-CoV2 -positive children presented with symptoms while the rest were asymptomatic (Figure 1).

The proportion of children screened increased over the study period, with an increasing trend in the positive cases from $0 \%$ in March, $12.5 \%$ in April, $18.5 \%$ in May and $15.6 \%$ in June, respectively (Figure 2). 


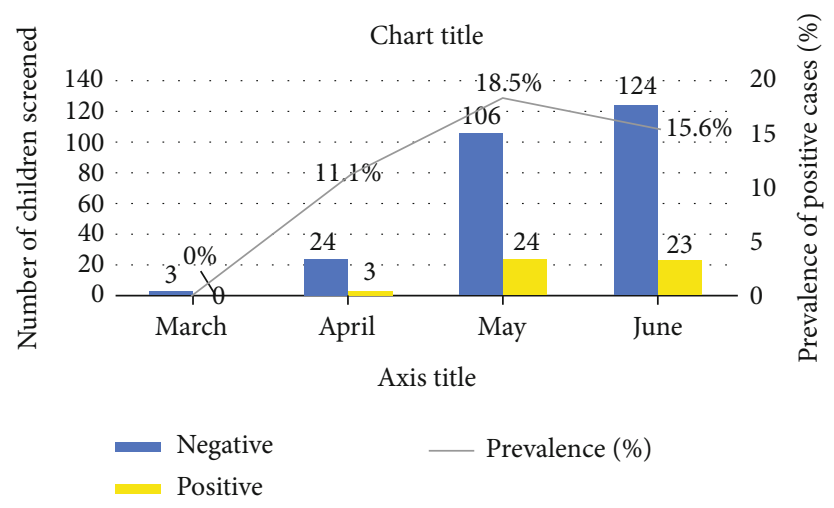

FIgURe 2: Pattern of children screened and outcomes.

The median (IQR) age of the children screened was 9 years (4-14 years). The majority were aged $\leq 9$ years (53.1\%), male (53.1\%), had evidence of BCG vaccination (64.2\%), and had recently travelled to a country with high COVID-19 incidence or come in contact with an individual with confirmed SARS-CoV-2 infection (59\%). Preexisting medical conditions were present in $5.5 \%$, and these included asthma $(3.9 \%, 12 / 307)$, congenital heart disease $(0.9 \%$, $3 / 307)$, and obesity $(0.7 \%, 2 / 307)$ (Table 1$)$.

The most common symptoms among the children screened for SARS-CoV-2 were fever (17.6\%), cough (10.1\%), runny nose $(11.4 \%)$, sore throat $(11.1 \%)$, and chest pain (5.2\%) Figure 3.

The median (IQR) age was 9 (4-14) years. There were 162 males and 145 females, giving a male:female ratio of $1.1: 1$. A majority had a positive history of BCG vaccination (64.2\%), contact with confirmed COVID-19 case or travel (59.0\%), and no preexisting medical condition (94.5\%). One hundred and twenty-six participants (41.0\%) presented with one or more symptoms. Fifty participants tested positive by RT-PCR to SARS-CoV-2 giving a prevalence of $16.3 \%$. There was no statistically significant difference in study variables among SARS-CoV-2-positive and SARSCoV-2-negative children. The age, gender, history of contact, BCG vaccinations, and symptomatology at presentation had no significant association with SARS-CoV-2 infection among the children screened (Table 2).

Fever, sore throat, and chest pain were significantly associated with being SARS-CoV-2 positive following univariate analysis, but this association was not evident with multivariate analysis (Table 3). The two reports of headache were found only among SARS-CoV-2-positive persons.

\section{Discussion}

The COVID-19 pandemic has had an impact on the continent. However, most information on the disease is focused on the adult population with limited information about the burden and pattern of the disease in the paediatric population, especially in sub-Saharan Africa.

The prevalence of SARS-CoV-2 infection among the paediatric population in our study $(16.3 \%)$ is within the prevalence range globally $(0.39 \%-34.1 \%)$. Similar studies
TABLE 1: Characteristics of the children screened for SARS-CoV-2 infection.

\begin{tabular}{lc}
\hline Characteristics & Patients (\%) \\
\hline Age group (years) & $6(2.0)$ \\
$<1$ & $75(24.4)$ \\
$1-4$ & $82(26.7)$ \\
$5-9$ & $70(22.8)$ \\
$10-14$ & $74(24.1)$ \\
$>14$ & \\
Sex & $144(46.9)$ \\
Female & $163(53.1)$ \\
Male & \\
Nationality & $277(90.2)$ \\
Nigerian & $30(9.8)$ \\
Non-Nigerian & \\
Preexisting medical condition & $290(94.5)$ \\
No & $17(5.5)$ \\
Yes & \\
History of contact/travel & $181(59.0)$ \\
Yes & $126(41.0)$ \\
No & \\
BCG vaccination & $190(16.3)$ \\
Yes & $110(35.8)$ \\
No/unknown & \\
Symptomatic & \\
Yes & \\
No & \\
SAR-CoV-2 test result & \\
Negitive & \\
\hline & \\
\hline & \\
Negative & \\
\hline
\end{tabular}

done within the same time frame as the current study reported prevalence between $0.39 \%$ and $34.1 \%$ [3, 8, 13-16].

The increase in the number of children screened for the COVID-19 and the subsequent rise in the prevalence from zero to $18.5 \%$ in the current study could be explained by the mandatory national policy of the need to screen close contacts of positive cases as well as Lagos state being the 


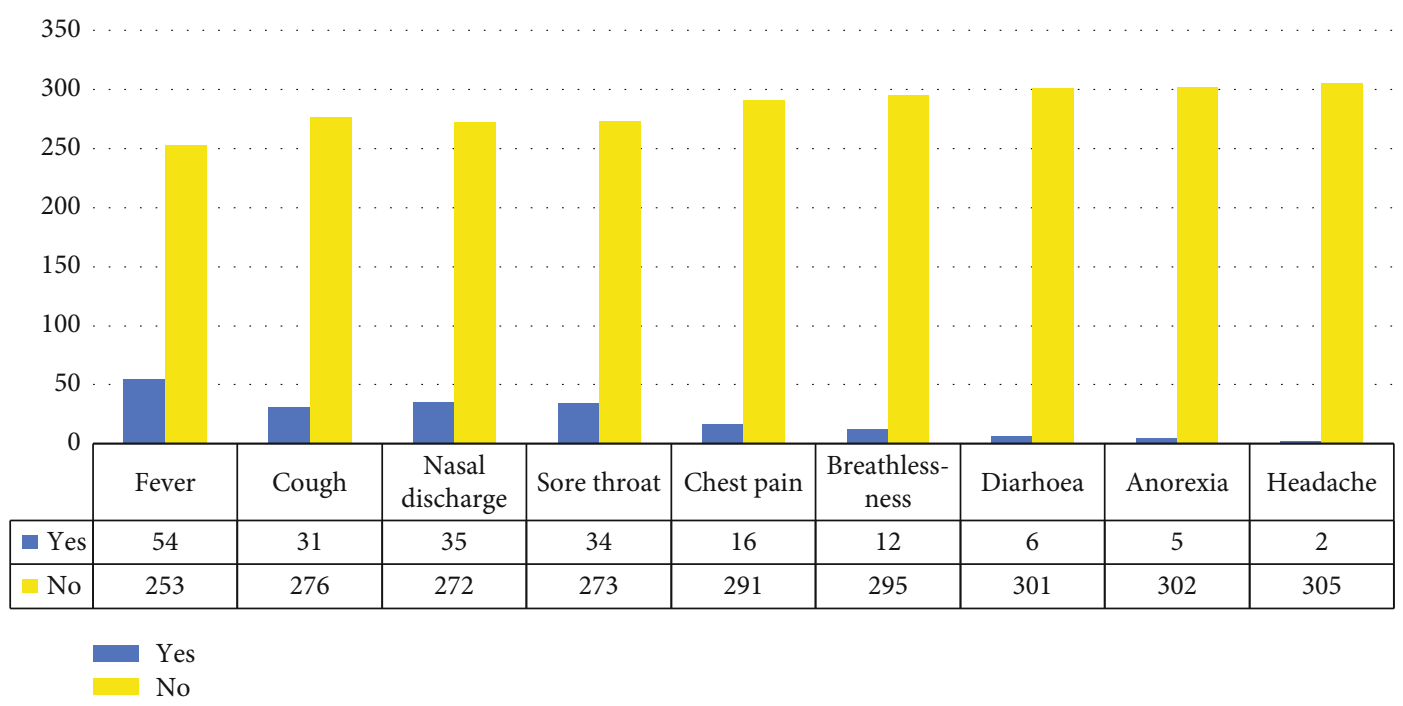

FIGURE 3: Symptomatology of the children screened for SARS-CoV-2.

TABle 2: Association between screening outcome and participants' characteristics.

\begin{tabular}{|c|c|c|c|c|c|c|c|}
\hline \multirow{2}{*}{ Characteristics } & \multirow{2}{*}{$\begin{array}{c}\text { All } \\
(n=307)\end{array}$} & \multirow{2}{*}{$\begin{array}{l}\text { SARS Pos } \\
(n=50)\end{array}$} & \multirow{2}{*}{$\begin{array}{c}\text { SARS Neg } \\
(n=257)\end{array}$} & \multicolumn{2}{|c|}{ Univariate } & \multicolumn{2}{|c|}{ Multivariate } \\
\hline & & & & OR $[95 \% \mathrm{CI}]$ & $p$ value & OR [95\% CI] & $p$ value \\
\hline Median age (IQR) (years) & $9.0(4.0-14.0)$ & $10.0(5.3-15.0)$ & $9.0(4.0-14.0)$ & & & & \\
\hline \multicolumn{8}{|l|}{ Age group (years) } \\
\hline$<10$ & $163(53.1)$ & $22(44.0)$ & $141(54.9)$ & \multirow{2}{*}{$1.55[0.87-2.85]$} & \multirow{2}{*}{0.159} & \multirow{2}{*}{$1.56[0.83-2.91]$} & \multirow{2}{*}{0.165} \\
\hline$\geq 10$ & $144(46.9)$ & $28(56.0)$ & $116(45.1)$ & & & & \\
\hline \multicolumn{8}{|l|}{ Sex } \\
\hline Male & $162(52.8)$ & $27(54.0)$ & $135(52.5)$ & \multirow{2}{*}{$1.06[0.58-1.95]$} & \multirow{2}{*}{0.849} & \multirow{2}{*}{$1.09[0.59-2.02]$} & \multirow{2}{*}{0.786} \\
\hline Female & $145(47.2)$ & $23(46.0)$ & $122(47.5)$ & & & & \\
\hline \multicolumn{8}{|l|}{ BCG } \\
\hline Yes & $197(64.2)$ & $32(64.0)$ & $165(64.2)$ & \multirow{2}{*}{$0.99[0.59-1.68]$} & \multirow{2}{*}{0.978} & \multirow{2}{*}{$0.99[0.51-1.94]$} & \multirow{2}{*}{0.986} \\
\hline No/not sure & $110(35.8)$ & $18(36.0)$ & $92(35.8)$ & & & & \\
\hline \multicolumn{8}{|l|}{ Contact/travel history } \\
\hline Yes & $181(59.0)$ & $31(62.0)$ & $150(58.4)$ & \multirow{2}{*}{$1.16[0.62-2.17]$} & \multirow{2}{*}{0.632} & \multirow{2}{*}{$1.15[0.59-2.24]$} & \multirow{2}{*}{0.689} \\
\hline No & $126(41.0)$ & $19(38.0)$ & $107(41.6)$ & & & & \\
\hline \multicolumn{8}{|l|}{ Preexisting condition } \\
\hline Yes & $17(4.5)$ & $1(2.0)$ & $16(6.2)$ & \multirow{2}{*}{$0.31[0.04-2.37]$} & \multirow{2}{*}{0.232} & \multirow{2}{*}{$0.34[0.04-2.74]$} & \multirow{2}{*}{0.313} \\
\hline No & $290(94.5)$ & $49(98.0)$ & $241(93.8)$ & & & & \\
\hline \multicolumn{8}{|l|}{ Symptoms } \\
\hline Yes & $126(41.0)$ & $17(34.0)$ & $109(42.4)$ & \multirow{2}{*}{$0.70[0.37-1.32]$} & \multirow{2}{*}{0.269} & \multirow{2}{*}{$0.70[0.37-1.34]$} & ( 202 \\
\hline No & $181(59.0)$ & $33(66.0)$ & $148(57.6)$ & & & & 0.283 \\
\hline
\end{tabular}

epicentre for the infection in the country. This finding affirms the human-to-human transmission and is similar to the trend reported by Dong et al. [16] in China.

Most of the children with COVID-19 disease in our study were asymptomatic or had mild symptoms, which is in keeping with previous reports $[8,16-20]$. The plausible explanations for this presentation among children aside from being a drive-through testing centre may be the robust innate immune system, weaker adaptive immune response, viral containment, or clearance in children [9, 10, 21-24]. Other postulations include recurrent exposure of children to viral infections modulating their responses to SARSCoV-2 [9, 10], the high level of melatonin in children in addition to its anti-inflammatory and oxidative properties (inhibiting SARS-CoV-2 infection through the blockage of the CD147 receptor) [25-27], exposure to live attenuated vaccine (BCG, OPV) [28-31], and low expression and function of the angiotensin 2 (ACE2) receptors [32, 33].

The pattern of symptomatology (fever, sore throat, cough, chest pain, and other gastrointestinal symptoms) among the screened population and confirmed SARS-CoV2 infection is similar to the case report series by Ibrahim 
TABLE 3: Comparison of symptoms among SARS-positive and SARS-negative participants.

\begin{tabular}{|c|c|c|c|c|c|c|c|}
\hline \multirow{2}{*}{ Symptoms } & \multirow{2}{*}{$\begin{array}{c}\text { All } \\
(n=126)\end{array}$} & \multirow{2}{*}{$\begin{array}{c}\text { SARS Pos } \\
(n=17)\end{array}$} & \multirow{2}{*}{$\begin{array}{l}\text { SARS Neg } \\
(n=109)\end{array}$} & \multicolumn{2}{|c|}{ Univariate } & \multicolumn{2}{|c|}{ Multivariate } \\
\hline & & & & OR [95\% CI] & $p$ value & OR $[95 \% \mathrm{CI}]$ & $p$ value \\
\hline \multicolumn{8}{|l|}{ Fever } \\
\hline Yes & $54(42.8)$ & $12(70.6)$ & $42(38.5)$ & \multirow{2}{*}{$3.82[1.26-11.64]$} & \multirow{2}{*}{0.013} & \multirow{2}{*}{$0.49[0.12-1.98]$} & \multirow{2}{*}{0.314} \\
\hline No & $72(57.2)$ & $5(29.4)$ & $67(61.5)$ & & & & \\
\hline \multicolumn{8}{|l|}{ Cough } \\
\hline Yes & $31(24.6)$ & $5(29.4)$ & $26(23.8)$ & \multirow{2}{*}{$1.33[0.43-4.13]$} & \multirow{2}{*}{0.621} & \multirow{2}{*}{$0.50[0.12-2.06]$} & \multirow{2}{*}{0.337} \\
\hline No & $95(75.4)$ & $12(70.6)$ & $83(76.2)$ & & & & \\
\hline \multicolumn{8}{|l|}{ Runny nose } \\
\hline Yes & $35(27.8)$ & $4(23.5)$ & $31(28.4)$ & \multirow{2}{*}{$0.77[0.23-2.56]$} & \multirow{2}{*}{0.674} & \multirow{2}{*}{$0.35[0.08-1.44]$} & \multirow{2}{*}{0.144} \\
\hline No & $91(72.2)$ & $13(76.5)$ & $78(71.6)$ & & & & \\
\hline \multicolumn{8}{|l|}{ Sore throat } \\
\hline Yes & $34(27.0)$ & $9(52.9)$ & $25(22.9)$ & \multirow{2}{*}{$3.78[1.32-10.82]$} & \multirow{2}{*}{0.009} & \multirow{2}{*}{$4.59[0.93-22.73]$} & \multirow{2}{*}{0.062} \\
\hline No & $92(73.0)$ & $8(47.1)$ & $84(77.1)$ & & & & \\
\hline \multicolumn{8}{|l|}{ Chest pain } \\
\hline Yes & $16(12.7)$ & $5(29.4)$ & $11(10.1)$ & \multirow{2}{*}{$3.71[1.10-12.51]$} & \multirow{2}{*}{0.026} & \multirow{2}{*}{$2.03[0.43-9.69]$} & \multirow{2}{*}{0.374} \\
\hline No & $110(87.3)$ & $12(70.6)$ & $98(89.9)$ & & & & \\
\hline \multicolumn{8}{|c|}{ Breathing difficulty } \\
\hline Yes & $12(9.5)$ & $2(11.8)$ & $10(9.2)$ & $132[026-662]$ & 0665 & $026[0.03-204]$ & 0201 \\
\hline No & $114(94.5)$ & $15(88.2)$ & $99(90.8)$ & $1.02[0.20-0.02]$ & 0.000 & $0.20[0.0 \mathrm{~J}-2.0 \mathrm{~T}]$ & 0.201 \\
\hline Diarrhea & & & & & & & \\
\hline Yes & $6(4.8)$ & $2(11.8)$ & $4(3.7)$ & $35[0-59-2079]$ & 0186 & $1056[073-15293]$ & 0084 \\
\hline No & $120(95.2)$ & $15(88.2)$ & $105(96.3)$ & $0.0[0.07-20.19]$ & 0.100 & $10.80[0.13-105.90$ & 0.004 \\
\hline Anorexia & & & & & & & \\
\hline Yes & $5(4.0)$ & $1(5.9)$ & $4(3.7)$ & $164\left[\begin{array}{lll}0 & 17 & 15 \\
152\end{array}\right]$ & 0.522 & $2031[056-72630]$ & 0099 \\
\hline No & $121(96.0)$ & $16(94.1)$ & $105(96.3)$ & $1.07[0.17-10.02]$ & 0.022 & 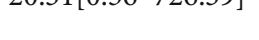 & 0.00 \\
\hline
\end{tabular}

et al. [34] in Nigeria. However, none of the cases reported by Ibrahim and his colleagues had gastrointestinal symptoms [34]. Furthermore, the pattern of symptoms in our review aligns with the clinical symptomatology of COVID-19 reported in children by Rahimzadeh et al. [35] in Iran, Le et al. [36] in Vietnam, the CDC COVID response team in the United States of America [8], and various other reports describing the symptomatology of the disease in the paediatric population [17-20]. This symptomatology of the SARSCoV-2 infections and its similarity to common childhood infections such as malaria, acute diarrhea diseases, and respiratory tract infection buttress the need for a high index of suspicion to ensure early diagnosis and prompt treatment.

There was slightly higher proportion of males infected with SARS-CoV-2, though without any significant difference noted with regard to gender and COVID-19 infection in the current study. The increased male predominance might be coincidental but could also be attributable to the increased ACE2 expression caused by testosterone in males as against the reversal effects by estrogens in females. Several previous studies have shown that the sex hormones androgens and estrogens influence the renin-angiotensin system. Androgens increase plasma renin activity and expression of angiotensinogen messenger RNA, while estrogens decrease plasma renin activity and angiotensin receptor expression [37-39]. This could explain the male predominance among
COVID-19 cases, though this hypothesis requires further evaluation in the affected population across all the age groups. The male predominance among the SARS-CoV-2infected children aligns with reports by CDC in USA [8], Guan et al. [18], and Dong et al. [16].

Contrary to reports of the association between age, BCG vaccination status, comorbid illness, and the COVID-19 infection in previous studies $[8,18]$, our findings did not show any association between the infection and the abovelisted variables. This could be because our facility is only a testing centre; other clinical data or extensive epidemiological review might proffer better clarity. However, the association of comorbid illness and BCG vaccination status requires more evidence-based findings beyond the scope of this report. The paediatric population at the centre appeared evenly distributed except for children aged below 12 months. This is not surprising considering the nature of our services contrary to other studies from hospitals or epidemiological data $[8,16-18]$.

This study is the first to describe the epidemiological and clinical characteristics of children screened for SARS-CoV-2 infection in sub-Saharan Africa. The clinical outcome of positive cases could not be ascertained as that data was not available to us. In addition, there could be information bias to the symptoms declared by caregivers on behalf of their wards. 


\section{Conclusions}

Fever and sore throat were associated with positive COVID19 results. The symptomatology of infected children is similar to other common childhood illnesses in the country (ARI, acute diarrhea diseases, viral infection, and malaria). A high index of suspicion is needed to combat the pandemic in the paediatric population among other health-promoting and preventive measures.

\section{Data Availability}

Access to this data is restricted due to the sensitive nature and stigma associated with COVID-19 in our setting.

\section{Conflicts of Interest}

The authors declare no competing interest.

\section{Acknowledgments}

We give our sincere appreciation to LifeBank and the management of NIMR towards the realization of this project as well as instituting the first drive-through SARS-CoV-2 testing centre in Lagos, Nigeria.

\section{References}

[1] D. S. Hui, E. I Azhar, T. A. Madani et al., "The continuing 2019-nCoV epidemic threat of novel coronaviruses to global health - The latest 2019 novel coronavirus outbreak in Wuhan, China," Int J Infect Dis., vol. 91, pp. 264-266, 2020.

[2] WHO, WHO Coronavirus Disease (COVID-19) Dashboard | WHO Coronavirus Disease (COVID-19) Dashboard, 2021, January 2021, https://covid19.who.int/.

[3] Z. Wu and J. M. McGoogan, "Characteristics of and important lessons from the coronavirus disease 2019 (COVID-19) outbreak in China," JAMA, vol. 323, no. 13, pp. 1239-1242, 2020.

[4] World Health Organization (WHO), Statement on the second meeting of the International Health Regulations (2005) Emergency Committee regarding the outbreak of novel coronavirus (2019-nCoV), Geneva, Switzerland, 2020May 2021, https:// www.who.int/news/item/30-01-2020-statement-on-thesecond-meeting-of-the-international-health-regulations(2005)-emergency-committee-regarding-the-outbreak-ofnovel-coronavirus-(2019-ncov).

[5] WHO, International Health Regulations, 91, 3rd edition, 2016, https://www.who.int/publications/i/item/9789241580496.

[6] The World Bank, Nigeria Overview, 2010.

[7] Nigeria Centre for Disease Control (NCDC), Covid-19 Situation Report: Situation Report 154, 2020, https://ncdc.gov.ng/ diseases/sitreps/?cat=14\&name $=$ An update of COVID-19 outbreak in Nigeria.

[8] S. Bialek, R. Gierke, M. Hughes, L. A. McNamara, T. Pilishvili, and T. Skoff, Coronavirus Disease 2019 in Children - United States, February 12-April 2, 2020, US Department of Health and Human Services/Centers for Disease Control MMWR Office, 2020.

[9] P. Zimmermann and N. Curtis, "Why is COVID-19 less severe in children? A review of the proposed mechanisms underlying the age-related difference in severity of SARS-CoV-2 infec- tions," Archives of Disease in Childhood, vol. 106, no. 5, pp. 429-439, 2021.

[10] P. C. M. Williams, A. R. Howard-Jones, P. Hsu et al., "SARSCoV-2 in children: spectrum of disease, transmission and immunopathological underpinnings," Pathology, vol. 52, no. 7, pp. 801-808, 2020.

[11] O. S. Amoo, A. G. Ohihoin, A. Z. Musa et al., "Implementation of a modified drive-through sampling strategy for SARS-CoV2-the Nigerian experience," Pan Afr Med J., vol. 35, Supplement 2, p. 107, 2020.

[12] Federal Ministry of Health \& Nigeria Centre for Disease Control, National Interim Guidelines for Clinical Management of COVID-19, 2020, https://covid19.ncdc.gov.ng/media/files/ National_Interim_Guidelines_for_Clinical_Management_of_ COVID-19_v3.pdf.

[13] Y. Li, F. F. Guo, Y. Cao, L. F. Li, and Y. J. Guo, "Insight into COVID-2019 for pediatricians," Pediatric Pulmonology, vol. 55, no. 5, pp. E1-E4, 2020.

[14] Korean Society of Infectious Diseases, Korean Society of Pediatric Infectious Diseases, Korean Society of Epidemiology, Korean Society for Antimicrobial Therapy, Korean Society for Healthcare-associated Infection Control and Prevention, and $\mathrm{KC}$ for DC and P, "Report on the epidemiological features of coronavirus disease 2019 (COVID-19) outbreak in the Republic of Korea from January 19 to March 2, 2020," J Korean Med Sci, vol. 35, no. 10, 2020.

[15] X. Lu, L. Zhang, H. du et al., "SARS-CoV-2 infection in children,” N Engl J Med, vol. 382, no. 17, pp. 1663-1665, 2020.

[16] Y. Dong, X. Mo, Y. Hu et al., "Epidemiology of COVID-19 among children in China," Pediatrics, vol. 145, no. 6, article e20200702, 2020.

[17] W. Xia, J. Shao, Y. Guo, X. Peng, Z. Li, and D. Hu, "Clinical and CT features in pediatric patients with COVID-19 infection: different points from adults," Pediatric Pulmonology, vol. 55, no. 5, pp. 1169-1174, 2020.

[18] W. Guan, Z. Ni, Y. Hu et al., "Clinical characteristics of coronavirus disease 2019 in China," The New England Journal of Medicine, vol. 382, no. 18, pp. 1708-1720, 2020.

[19] P. Zimmermann and N. Curtis, "COVID-19 in children, pregnancy and neonates: a review of epidemiologic and clinical features," The Pediatric Infectious Disease Journal, vol. 39, no. 6, pp. 469-477, 2020.

[20] T. Waterfield, C. Watson, R. Moore et al., "Seroprevalence of SARS-CoV-2 antibodies in children: a prospective multicentre cohort study," Archives of Disease in Childhood, vol. 106, no. 7, pp. 680-686, 2021.

[21] C. M. Lau, N. M. Adams, C. D. Geary et al., "Epigenetic control of innate and adaptive immune memory," Nature Immunology, vol. 19, no. 9, pp. 963-972, 2018.

[22] M. G. Netea, J. Domínguez-Andrés, L. B. Barreiro et al., "Defining trained immunity and its role in health and disease," Nature Reviews Immunology, vol. 20, no. 6, pp. 375-388, 2020.

[23] A. Fischer, "Resistance of children to Covid-19. How?," Mucosal Immunology, vol. 13, no. 4, pp. 563-565, 2020.

[24] R. Valiathan, M. Ashman, and D. Asthana, "Effects of ageing on the immune system: infants to elderly," Scandinavian Journal of Immunology, vol. 83, no. 4, pp. 255-266, 2016.

[25] R. Hardeland, "Melatonin and inflammation-story of a double-edged blade," Journal of Pineal Research, vol. 65, no. 4, pp. 1-23, 2018. 
[26] X. Wu, H. Ji, Y. Wang et al., "Melatonin alleviates radiationinduced lung injury via regulation of miR-30e/NLRP3 axis," Oxidative Medicine and Cellular Longevity, vol. 2019, Article ID 4087298, 14 pages, 2019.

[27] S. C. Miller, P. S. R. Pandi, A. I. Esquifino, D. P. Cardinali, and G. J. M. Maestroni, "The role of melatonin in immunoenhancement: potential application in cancer," International Journal of Experimental Pathology, vol. 87, no. 2, pp. 81-87, 2006.

[28] A. J. Pollard, A. Finn, and N. Curtis, "Non-specific effects of vaccines: plausible and potentially important, but implications uncertain," Archives of Disease in Childhood, vol. 102, no. 11, pp. 1077-1081, 2017.

[29] J. P. T. Higgins, K. Soares-Weiser, J. A. López-López et al., "Association of BCG, DTP, and measles containing vaccines with childhood mortality: systematic review," BMJ, vol. 355, article 5170, 2016.

[30] S. J. C. F. M. Moorlag, R. J. W. Arts, R. van Crevel, and M. G. Netea, "Non-specific effects of BCG vaccine on viral infections," Clinical Microbiology and Infection, vol. 25, no. 12, pp. 1473-1478, 2019.

[31] E. J. Giamarellos-Bourboulis, M. Tsilika, S. Moorlag et al., "Activate: randomized clinical trial of BCG vaccination against infection in the elderly," Cell, vol. 183, no. 2, pp. 315-323.e9, 2020.

[32] E. Ciaglia, C. Vecchione, and A. A. Puca, "COVID-19 infection and circulating ACE2 levels: protective role in women and children," Front Pediatr, vol. 8, p. 206, 2020.

[33] P. Palmeira, J. A. M. Barbuto, C. A. A. Silva, and M. CarneiroSampaio, "Why is SARS-CoV-2 infection milder among children?," Clinics, vol. 75, p. 5, 2020.

[34] O. R. Ibrahim, B. M. Suleiman, A. Sanda et al., "Covid-19 in children: a case series from Nigeria," The Pan African Medical Journal, vol. 35, no. Supp 2, pp. 1-4, 2020.

[35] G. Rahimzadeh, M. Ekrami Noghabi, F. Kadkhodaei Elyaderani et al., "COVID-19 infection in Iranian children: a case series of 9 patients," J Pediatr Rev, vol. 8, pp. 139-144, 2020.

[36] H. T. le, L. V. Nguyen, D. M. Tran et al., "The first infant case of COVID-19 acquired from a secondary transmission in Vietnam," Lancet Child Adolesc Heal., vol. 4, no. 5, pp. 405-406, 2020.

[37] B. B. McGuire, R. W. G. Watson, F. Pérez-Barriocanal, J. M. Fitzpatrick, and N. G. Docherty, "Gender differences in the renin-angiotensin and nitric oxide systems: relevance in the normal and diseased kidney," Kidney \& Blood Pressure Research, vol. 30, no. 2, pp. 67-80, 2007.

[38] D. M. Rabi, N. Khan, M. Vallee, M. A. Hladunewich, S. W. Tobe, and L. Pilote, "Compte rendu d'une analyse selon le sexe d'essais cliniques sur l'efficacite de l'inhibiteur de l'enzyme de conversion de l'angiotensine et des antagonistes de l'angiotensine," The Canadian Journal of Cardiology, vol. 24, no. 6, pp. 491-496, 2008.

[39] M. C. White, R. Fleeman, and A. C. Arnold, "Sex differences in the metabolic effects of the renin-angiotensin system," Biology of Sex Differences, vol. 10, no. 1, pp. 31-18, 2019. 